\title{
Jazzing Up The Psychological Contract
}

\author{
Nell Tabor Hartley, Robert Morris University, USA
}

\begin{abstract}
Helping students and practitioners to understand and utilize the Psychological Contract is often a difficult task. Unlike fault-finding research, this paper presents the PC as a positive, vibrant and valuable tool. In an effort to make the concept less elusive, the paper draws upon the metaphor of jazz. The metaphor is an accepted tool of learning. Both jazz and the Psychological Contract build upon new themes and accept occasional dissonance and are able to benefit from creative tension.
\end{abstract}

Keywords: Psychological Contract Cooperation Mutuality

\section{INTRODUCTION}

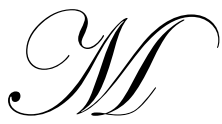

anagement is both art and science! The marriage of the two is nowhere more apparent than in the Psychological Contract. The Psychological Contract (PC) is a name, somewhat metaphorical, for the tacit agreement between employer and employee.

The PC is a concept developed in 1980 by Chris Argyris and given prominence by Denise Rousseau (Smithson \& Lewis, 2003). The concept represents for many a clash between the values that are espoused in the workplace and those that are enacted. While students intuitively appreciate the reality of the disconnect, they find it difficult to verbalize and apply an actual theory which is inherently fluid and spontaneous. One cannot measure PC activities, nor is there a standard PC procedures manual to give newcomers. Additionally, the contract relies on decisions that are made skillfully and are fueled with intuition, much the same way that jazz musicians gather and play their instruments (Rousseau, 2001).

Having made that connection, consider using jazz as a metaphor to help students synthesize and evaluate the PC (Forehand, 2005). Metaphors are an accepted tool of explanation and illustration. Life is rich with metaphors and metaphors, in the hands of skilled artisans through the ages, have provided lenses through which we view and better comprehend life. From the antiquity of Aesop to the old world of William Shakespeare into the contemporary world view of Jim Collins, thinkers have painstakingly utilized their respective crafts to illuminate the metaphor in order to provide the layman new understanding.

\section{DEFINITIONS}

In defining the psychological contract, some, but not all scholars, stress the inherent implication of mutuality and reciprocity, based on the perceptions of both parties (employee and employer or its agent e.g. managers(Rousseau, 1995a)). Students find those terms to be elusive. Educated in pursuing the literal, many students struggle with anything that lacks defined boundaries and specific contexts. Using qualitative rhetoric with students often does not work. Students seem less threatened discussing ideas associated with leisure such as music. Ask that they envision a group of jazz musicians jamming. Using jazz as a metaphor for the PC opens the doors of comprehension.

The idea to use music as a metaphor is not unique! Music and employment both require the skill and the ability of the participant. Music terminology finds its way into discussions of decision making and implementation: e.g., one orchestrates a decision. Authors of an article about Chester Barnard titled their article "Playing by ear..." (Novicevic, 2002). Agreeably, jazz is a universal language for communicating ideas and emotions. "...musical concerns such as technique, listening and preparation all provide a stimulating insight into familiar management concerns" (Bexson, 2002). 
Jazz, more than the symphony, is the metaphor to use. Jazz draws upon the musicians' intuition and flexibility in goal achievement. In a symphony orchestra, musicians play prescribed notes within established bars. Jazz, like the PC, is built upon subtleties.

Discernable tensions help create jazz. Interestingly, tension is inherent in the nomenclature of the psychological contract. Psyche refers to the unseen; contract implies documentation. Orchestrated music requires a written score, certain sounds and tempos and specified instruments, Jazz, in its improvisational, innovative and responsive ways, embodies those same traits found in the PC. Each has characteristics that require trust. In addition, each is built on a natural ebb and flow between people. This ebb and flow demands the recognition of community. Jazz players build their community through "participating in a discipline that has its own set of social practices, implicit rules, and musical theory (Bastien \& Hostager, 1991). Building a community with respect to a PC provides implicit rules and is built on theories of respect and Emotional Intelligence. The environment in which a PC has strength is one in which participants are willing to "suspend their assumptions that they hold ... recognizing that they may be incorrect... while at the same time paying serious attention to habitual thought and emotional reflexes within the group" (Bohm, 1991).

\section{PARTICIPANTS}

The links between stakeholders of the PC are fluid; so too musicians involved in the jazz community are not static links; they are more akin to feedback loops. Kunstler (2004) says of the feedback loops of jazz that "they are actually feedback loops in which one person's innovation links up with scores of musicians and thousands of fans who transmit their verdicts, or feedback, along the channels linking the cities, musicians, and fans" (Kunstler, 2004). The synergistic music that occurred as Charlie Parker and Miles Davis played solos, together, and in tandem can be symbolic of the successful results of the corporate community's participation in orchestrating responses to challenge. The parallel is obvious.

Musicians and workers operate as communities and as individuals. In both instances there is respect for the individual both on center stage and in isolation. Within a community of innovation and respect, individuals can enrich the perspectives, and responses of others while also challenging them. The concept that individuals are more creative when permitted to derive their power and integrity from group social dynamics is well documented. A prime example of this has been the group of people who invented computers. (Brown \& Duguid, 2001).

Within community there must also be individuality. Individuality is integral to the definition of diversity. The healthiest, and most productive, definition of diversity is individuality, not race, sex, or some other governmental/regulatory definition. Sociologists insist that we must learn to make distinctions based on this new awareness and value of individuality, so that the organizations in which we work, and society at large will be all the better for it (Putzier, 2004). The PC demands respect of individuality. Jazz sessions bring together different individual instrumentalists. Each musician is respected for his unique style. And, there will be times when individuals have "their moment." A musician will solo. So too, will participants of the PC. There are times when an individual needs to be permitted to shine. To know one's strengths and to showcase them is part of success in both musical and business successes.

People in business need to build on their strengths much as musicians practice their instruments! Sometimes this seems pointless to employees when faced with employers who may talk idealistically about synergistic teamwork, corporate diversity and learning cultures, but whose actions speak a preference for the company of clones and teamwork within mono-cultural corporate communities i.e. homogenous groups are easier to maintain (Nicholson, 2001).

\section{CREATIVITY}

The definition and perception of 'normal' has expanded. Whatever our religious, political, or societal values and convictions, we cannot escape the reality that we are not all the same, and that society, particularly American society, is increasingly rewarding individuality and extreme behavior - a new 'normal' (Putzier, 2004). Creative people know the importance of time alone. Thoreau found the wilderness to be his "tonic" (Thoreau, 1904). 
Musicians recognize the importance of solitude. In describing the Hothouse Effect, Kunstler repeatedly describes the importance of solitude in the creative process. The importance of solitude -individuals' personal assessment of their place in the "score" -parallels the employees' deliberations about their role within the organization and their personal aspirations and challenges. This need for time alone time may well be suggested as part of workers' psychological contract with one another. People caught in the pressures of getting more accomplished in less time have allowed the once popular lunch hour to be replaced by a nutrition bar or sandwich at the desk. Psychologists tell us: " ... solitude is an important route to creativity; indeed research suggests...that the most talented youngsters are those who treasure their solitude." (Buchholz, 1998). Music, and managing both work and home call for creative solutions and creative solutions call for solitude. In quiet times our unconscious is able to hear notes, and to process and unravel the problems we face.

Jazz is creative and is not always rewarded. To be creative is to take risk. Society itself resists creativity, commitment and trust. The artist or thinker may challenge long-standing beliefs or behavioral and political norms. An invention may threaten to throw many people out of work. An inventor or scientist may be so far ahead of his time that colleagues cannot accept his or her findings. Copernicus, for example, anticipated trouble with his description of the solar system and would not let it be published until his death.

Klein writes of the reality that organizations may actually punish creativity and reward the avoidance of creativity (Klein, 1990). Everyone is not a willing jazz musician, nor is each person within a corporation an advocate of personal empowerment. Having strong survival instincts, we hang on to what has worked in the past. Many musicians prefer the old, familiar order and prefer the reliability that each measure will be played at the same tempo in each performance. Part of the magic of jazz is that the players in the ensemble all of the same base line yet they hear and respond to it slightly differently. Books are written to encourage people to look creatively at their work performance. Is there a way to "think outside of the box"? A common question: why are we unable to see things differently. Why don't we look for change in our lives? We sit at a different place at the dinner table or drive a new route to work? One answer: we do not need to be creative for most of what we do in the daily routines of life. We are creatures of habit when it comes to daily living. Staying on familiar thought-paths enables us to do the many things we need to do without having to think about them (Von Oech, 1998).

Putzier, Von Oech, and Rousseau are all giving guidance for attaining self efficacy. Self efficacy gives people confidence to explore. Many of us have been taught that the best ideas are in somebody else's head. Part of our job is to somehow know others' cognitive expectations of us: the teacher, the supervisor, etc. Why don't we first consider our own thoughts and attitudes? What do we know about ourselves that allows us to play in a jazz ensemble or explore the benefits of speaking up? Self-knowledge is important for anyone who wished to play in a jazz ensemble or effectively and creatively orchestrate as stress-free as possible work environment

\section{CONTEXT}

But how does one measure the PC? Those who are dismissive of the value of the PC are concerned that there is no measurement of its effectiveness (Roehling, 1997). Often the psychological contract is measured indirectly, i.e., via commitment and loyalty, which is contentious, or in terms of contract breach (Kickul, Neuman, Parker \& Finkl, 2001). Others recognize the qualitative nature to be a positive. One cannot measure the impact of jazz. It is affective more than cognitive. Similarly, jazz stirs the emotions and generates attitudes. So too the PC is a concept of affect, attitude and emotion. Each has versatility. "The psychological contract's versatility suggests that it, along with related constructs such has a central role to play in organizational behavior by better specifying the dynamics of the employment relationship" (Harwood \& Rousseau, n. d.).

But there is with both the jazz metaphor and the contract a need to understand the context of their existence. Employees like musicians, must understand where they fit in relation to the company goals. Musicians look for their places in reference to the base line. It is only after identifying one's relationship to the "base line" (an object of performance appraisals) that one is able to determine the appropriateness of remaining on stage, or with an employer. While the music may continue, all musicians do not participate at all times. Abbott Laboratories is an example of a company that understands that individuals will depart from the base line. Flexibility within a structure is important. A former executive of Abbott commented that objectives for the year were written in concrete, but the 
plans were meant to be modified. ${ }^{1}$ Our minds remain cluttered with ready-made answers, and we too seldom entertain modifications or new perspectives i.e.., the psychological contract (Von Oech, 1998).

Where is the leadership? Within companies, leaders emerge or are recruited or hired from external organizations. Consider the jazz metaphor in terms of leadership. There is not the structure that defines classical music. In classical music, as in hierarchal organizations, the baton of leadership is rewarded to one person, usually after he or she has had years of preparation. Individual sections of instruments designate "first" chair. So, too, in classical management, positions have been initiated and dictated in hierarchal fashion. Often compliance, rather than commitment, to organizational goals is achieved. "My way or the highway" has been a classical performance "mantra." Current theorists disagree. In a culture of complexity, the chief role of leadership is to mobilize the collective capacity to challenge difficult circumstances.(Fullan, 2001).

The PC promotes an organizational culture of shared leadership and coaching; one focused on developing people, not one of using people as instruments of profit. The leadership of jazz groups tends to be democratic and often shared. The musicians of jazz are from every walk of life, multiple races, and both genders. In jazz, the members of the ensemble understand that they determine the success of their leaders. The PC can affect a similar awareness among the rank and file. Members of a jazz group are committed to the goal. Such internal commitment cannot be activated from the top; it must be nurtured up close in the daily-ness of organizational behavior, and for that to happen, there must be recognition that many of those in the group are potential leaders. Large organizations can never achieve perfect internal commitment, but with good leadership at all levels they can generate a great deal of it, and this will feed on itself (Lee, 1971; Buckingham \& Coffman, 1999). Large organizations would do well to recognize servant leadership as well as committed followers. In a jazz ensemble, an instrumentalist may be the strongest player who encourages the others. Depree (1992), whose book on leadership is built on the jazz metaphor, encourages leaders to empower followers. He writes that a wise leader remains ignorant about some things so that she can trust others to do what she is not able to do.

In some arenas, the PC is an unknown, or if known ignored. In support of understanding the implications that the "jazz metaphor" might have for increasing adherence to the PC, one evaluates the openness of people to change. What is the potential that people will change their view when faced with a novel idea as compared to functioning against a backdrop of the status quo and ingrained assumption? Those who want us to try a more open and trusting system create enemies in all those who profit by the old order and only lukewarm defenders among those who could profit by the new order. This lukewarmness arises from the incredulity of people who do not truly believe in anything new until they have had actual experience with it. Think of people who do not like jazz and who do not want to hear it ...for the first time (Black \& Gregersen, 2002).

What is the willingness of workers to "jam" with fellow employees; their willingness to be vulnerable, to participate, and to make decisions? And finally to what extent do they know themselves, their own needs, risk tolerance, and flexibility? At what point, metaphorically, will they put down their instrument and walk off of the stage.

In researching great companies, Collins recognized individualistic characteristics such as "creative urges" and inner compulsions to achieve for achievement's sake (Collins, 2001). Daniel Golman's work on Emotional Intelligence focuses on the importance of self-awareness, self regulation and self-regard (Fullan, 2001). Bridges in his work on change management insists that people understand their core competencies which lead to creative responses to change. He elaborates that change creates unmet needs by rendering many things and ideas obsolete (Bridges, 1994).

The managers who want to be successful within the "jazz club of global competition" are not soloists who play better than the rest. They are not conductors of big orchestras looking for approval, but artists that bring out the best in others, applaud them, and determine the guidelines like selecting the right place, choosing the right time, fixing the limits, and borders (Walzer \& Salcher, 2003).

${ }^{1}$ George Rathmann interview in Good to Great Jim Collins (New York: Harper Collins) 2002 p.122 


\section{CONCLUSION}

In these turbulent times the PC can be a valuable instrument in the struggle for survival. Many of the topics of a global economy require that we find finding common understandings, approach change creatively, and ready ourselves for action (Walzer \& Salcher, 2003). While the notion of 'managing creativity' may seem to be an oxymoron, we can strive for balanced flexibility and foster conditions that favor creative expression. We must work to provide environments which serve as incubators for change. Numerous writers suggest that it is perhaps the managerial challenge of the century to find a way to tap into that creative drive which is present, however hidden, in the hearts and minds or every human being. A metaphor for finding and maintaining creative tension is again in the instruments that create jazz. Many of the instruments have strings. The correct tension in the strings is necessary for maximum production of quality sound. Bringing about change in the way that we work together is an awesome task. Change, though not a stringed instrument, calls for an appropriate tension. Too little change or too much change is harmful to the functioning of the organization. A tuning fork or a psychological contract ... each is a tool. Rousseau calls for research into the success of the PC tool; for an understanding of the inherent cycle of exchange that creates commitment. (Rousseau, 1995).

With all that we are learning, let us step aside from positions in the audience of classical music and take our seats as participants in the jazz ensemble. The music is starting.

\section{AUTHOR INFORMATION}

Nell Tabor Hartley holds a BA degree from Agnes Scott College, the MS from the University of Illinois, Eds. From George Peabody College for Teachers, and Ph.D. from Vanderbilt University. Her university teaching, corporate consulting career and participation in vocal groups spans two decades. Readers of The Journal of Management History may be familiar with the 2006 Umbrella Model that she created as a tool for helping students understand the relevance of historical theories.

\section{REFERENCES}

1. Batien, D., \& Hostager, T. (1988). Jazz as a Process of Organizational Innovation. Communication Research, 15(5). Retrieved from http://crx.sagepub.com/cgi/content/abstract/15/5/582.

2. Bexson, T. (2002). Evening Standard. Retrieved from http://www.musicandmanagement.com/eveningstandardarticle.php.

3. Black, J.S., \& Gregersen, H.B. 2002. Leading strategic change: Breaking through the brain barrier. New Jersey: Financial Times Prentice Hall.

4. Bohm, D. (1990). On Dialogue. David Bohm Seminars: Ojai, California.

5. $\quad$ Bohm, D. (1996). On Dialogue. London: Routledge.

6. Bridges, W. 1991. Transitions: Making the Most of Change. New York: Perseus Books.

7. Brown, J. \& Duguid, P. (2001). Knowledge and Organization: A Social-Practice Perspective. Organizational Science, 12(2). Retrieved from http://orgsci.journal.informs.org/cgi/content/abstract/12/2/198

8. Buchholz, Ester. (1998). The Call of Solitude. Psychology Today. Retrieved from http:// www.psychologytoday.com/articles/199802/the-call-solitude.

9. Buckingham, M. \& Coffman, C. (1999). First Break All the Rules: What Managers do Differently. New York: Simon \& Schuster.

10. Collins, J. (2001). Good to Great: Why some companies make the leap and others don't. New York: HarperCollins.

11. Dale, K. \& Fox, M. (2008). Leadership Style and Organizational Commitment: Mediating Effect of Role Stress. Journal of Managerial Issues, 20.

12. Depree, M. (1992). Leadership jazz. New York: Dell Publishing.

13. Forehand, M. (2005). Bloom's taxonomy: Original and revised. In M. Orey (ed.), Emerging perspectives on learning, teaching, and technology. Retrieved $\langle 10 / 30 / 2009\rangle$, from http://projects.coe.uga.edu/epltt/index.php?title=Bloom\%27s_Taxonomy

14. Fullan, M. (2001). Leading in a culture of change. San Francisco: Jossey-Bass. 
15. Hartley, N., Gartley, W., \& Putzier, J. (Eds.). (2005). Proceedings from Midwest Academy of Management: JAZZ as an International Metaphor for Change. Chicago, Illinois: Midwest Academy of Management.

16. Harwood, R. (Interviewer) \& Rousseau, D. (Interviewee). (n. d.). The Role of the Psychological Contract in the Contemporary Workplace [Interview transcript]. Retrieved from Rafe Harwood Website: http://www.unfortu.net/ rafe/links/rousseau.htm

17. Kickul, J., Neuman, G., Parker, C. \& Finkl, J. Setting the Score: The Role of Organizational Justice in the Relationship Between Psychological Contract Breach and Anticitizenship Behavior.

EmployeeResponsibilities and Rights Journal, 13: 90-1.

18. Klein, A. R. 1990. Organizational barriers to creativity and how to knock. The Journal of Services Marketing, 4(4): 69-70.

19. Kunstler, Barton. (2004). The Hothouse Effect. New York: AMACOM.

20. Lee, S. An empirical analysis of organizational identification. 1971. Academy of Management Journal, 14, 213-226.

21. Nicholson, N. (2001). Developing the leader within you. Nashville: Thomas Nelson.

22. Novicevic, M., Hench, T., Wren, D. 2002. "Playing by ear"..."in an incessant din of reasons": Chester Barnard and the history of intuition in management thought. Management Decision, 40(10), 992-1003.

23. Palmer, Parker. (1998). The Courage to Teach. San Francisco: Jossey-Bass.

24. Putzier, J. 2004. Weirdos in the workplace. New Jersey: Financial Times Prentice Hall.

25. Rousseau, D. (1995a). Psychological contracts in organizations: Understanding written and unwritten agreements. Thousand Oaks: Sage.

26. Rousseau, D. \& Wade-Benzoni, K. (1995b). Changing individual-organizational attachments: A two-way street. In A. Howard (Ed.), The changing nature of work. Jossey Bass.

27. Rousseau, D. 1998. The problem of the psycholofical contract considered. Journal of Organizational Behavior, Vol. 19, 665-671.

28. Rousseau, D. 2001. Schema, promise and mutuality: The building blocks of the psychological contract. Journal of Occupational and Organizational Psychology, 74: 511-541.

29. Smithson, J. \& Lewis S. (2003). Psychological Contract. WF Network Encyclopedia. Retrieved from http://wfnetwork.bc.edu/encyclopedia_entry.php?id=250

30. Thoreau, H. D. (1904). Walden. London: George Routledge \& Sons Limited.

31. Von Oech, R. 1998. A whack on the side of the head. New York: MJF Books.

32. Walzer, N., \& Salcher, A. 2003. Management by jazz: Creating innovation from the principles of chaos and order. Industrial and Commercial Training, 35: 67-70. 